\title{
ASPEK BIOLOGI PARI MONDOL (Himantura gerrardi) FAMILI DASYATIDAE DARI FERAIRAN LAUT JAWA
}

\author{
Wiwiet An Pralampita") dan Siti Mardlijah"
}

\begin{abstract}
ABSTRAK
Penelitian tentang aspek biologi pari, khususnya hasil tangkapan perairan Laut Jawa sangat sedikit. Untuk itu, telah diadakan penelitian tentang aspek biologi pari mondol (Himantura gerrardi) famili Dasyatidae dari perairan Laut Jawa. Data dikumpulkan dari 4 pusat pendaratan ikan, yaitu Cirebon, Tegal, Juwana, dan Brondong selama tahun 2002 sampai dengan 2003. Pengamatan dan analisis dilakukan terhadap beberapa aspek biologi yang meliputi ukuran lebar cawan, bobot, tingkat kematangan gonad, dan nisbah kelamin. Dari hasil analisis diketahui bahwa hubungan panjang bobot pari H. gerrardi bersifat isometrik di mana pertambahan lebar cawan seimbang dengan pertambahan bobotnya, tingkat kematangan gonadnya lebih beragam. Ukuran pertama kali matang ikan pari jantan adalah pada lebar cawan $37,30 \mathrm{~cm}$ dan pada ikan pari betina pada lebar cawan $48,22 \mathrm{~cm}$ dan kesinambungan populasinya berjalan dengan baik.
\end{abstract}

KATA KUNCI: Ikan pari, Himantura gerrardi, aspek biologi, perairan Laut Jawa

ABSTRACT: Biological aspects on pani mondol (Himantura gerrardi) famili Dasyatidae from Java Sea waters. By: Wiwiet An Pralampita and Siti Mardiljah

The research on the biological aspects of rays, especially caught in Java Sea waters, is very limited. For this reason, the research on biological aspect of mondol rays (Himantura gerrardi) famili Dasyatidae was undertaken in Java Sea waters. The data were collected from four landing places i.e. Cirebon, Tegal, Juwana, and Brondong in the periode of 2002 to 2003. The observation and analysis were carried at disk width out on the biological aspects including disk width, weight, sex ratio, and gonad maturity. The results show that length weight relationship of $\mathbf{H}$. gerrardi was isometric where both disk width and body weight grew equally, gonad maturity stage is divers. The length at first maturity $(\mathrm{Lm})$ were of 37.30 for male rays and $\mathrm{Lm} 48.22 \mathrm{~cm}$ for female rays and the continuity of population is going on the good condition.

KEWWORDS: $\quad$ rays, Himantura gerrardi, biological aspects, Java Sea waters

\section{PENDAHULUAN}

Pada umumnya data biologi pari dan kelompok ikan bertulang rawan (Elasmobranchii), kurang tersedia secara memadai bila dibanding dengan data dan informasi yang sama untuk berbagai jenis ikan bertulang keras (Teleostei) (Castro et al., 1999). Terdapat beberapa alasan tentang jarangnya pengetahuan dasar biologi pari yaitu 1) insentif ekonomi dan dorongan untuk mempelajari pari sangat kecil, terutama ketika nilai komersial daging pari berada jauh di bawah nilai ekonomi dari berbagai jenis ikan bertulang keras, seperti tuna, makerel, kakap merah, kerapu, dan lain-lain; dan 2) lebih disebabkan oleh masalah biaya dan logistik, sehingga mengakibatkan perolehan spesimen yang tidak memadai. Sebagian besar pari mempunyai kombinasi karakteristik biologi yang tidak umum, yakni mempunyai laju pertumbuhan dan kematangan seksual yang lambat; siklus produksi yang panjang; fekunditas rendah; dan rentang hidup yang panjang (FAO, 2000; Castro et al., 1999; Compagno, 1998; Last \& Stevens, 1994), sehingga populasi di alam dikuatirkan semakin menurun jika aktivitas penangkapan tidak dikontrol lebih serius.
Selama ini Indonesia tidak memiliki data statistik hasil tangkapan pari menurut spesies, yakni data yang sangat diperlukan untuk mengetahui kecenderungan jumlah dan komposisi spesies hasil tangkapan yang didaratkan. Data dan informasi in sangat berguna sebagai indikator status perikanan pari di Indonesia. Kepedulian mengenai penangkapan berlebih dan kehancuran (collapse) dari sejumlah stok pari telah mendorong berbagai upaya untuk mengelola dan melestarikan pari. Keberhasilan mengelola dan melestarikan pari sangat ditentukan oleh berbagai faktor, antara lain berupa pemahaman yang lebih baik tentang perikanan pari dan efek yang ditimbulkannya, termasuk efek biologi dari spesies target, sehingga pengumpulan data biologi yang bersifat spesifik spesies dari perikanan pari sangat diperlukan. Agar pengumpulan data ini dapat dilaksanakan dengan baik, maka terlebih dahulu diperlukan kemampuan melakukan identifikasi spesies pari dengan benar.

Sampai saat ini, penelitian pari di Indonesia pada taraf yang sangat awal, langka dan terbatas pada kegiatan identifikasi spesies, pengukuran panjang dan bobot, penentuan nisbah kelamin, dan observasi pada

Peneliti pada Balai Riset Perikanan Laut, Jakara 
perikanan artisanal. Penelitian pendahuluan ini dimaksudkan untuk mengisi kelangkaan data dan informasi yang diperlukan untuk melestarikan dan mengelola perikanan pari terutama dalam hal 1) identifikasi jenis; 2) nisbah kelamin; dan 3) ukuran panjang dan distribusi frekuensinya yang merupakan hasil tangkapan dari perairan Laut Jawa.

Informasi yang akurat dari hasil penelitian ini sangat berguna sebagai dasar kegiatan pemanfaatan (eksploitasi) yang berkelanjutan (sustainable) dan sekaligus mendukung program International Plan of Action dari FAO berkaitan dengan konservasi dan pengelolaan dari Elasmobranchii. Selanjutnya, International Plan of Action harus diterjemahkan menjadi National Plan of Action terutama bagi negaranegara yang melakukan pemanfaatan ikan-ikan Elasmobranchii seperti Indonesia.

\section{BAHAN DAN METODE}

Pari mondol, H. gerrardi diperoleh dari hasil tangkapan nelayan jaring cantrang dan pancing senggol di perairan Laut Jawa. Contoh pari dikumpulkan dari 4 pusat pendaratan ikan di perairan Laut Jawa yaitu pusat pendaratan ikan Cirebon, i egal, Juwana, dan Brondong selama tahun 2002 sampai dengan 2003. Penarikan contoh pari dilakukan secara acak terhadap hasil tangkapan dalam jumlah spesimen banyak (lebih dari 10) dan diambil semuanya bila jumlah spesimen sedikit (kurang dari 10). Identifikasi jenis dilakukan dengan menggunakan sejumlah referensi, yakni Last \& Stevens (1994), Sainsbury et al. (1985), Tarp \& Kailola (1982), Carpenter \& Niem (1999), dan Bruin et al. (1994). Pengukuran lebar cawan (width disk) pari dilakukan menggunakan pita pengukur panjang dengan ketelitian $1 \mathrm{~mm}$, dan jumlah pari jantan dan pari betina dipisahkan berdasarkan pada tingkat kematangan gonad. Penentuan jenis kelamin dilakukan dengan pengamatan terhadap adanya sepasang klasper (untuk pari jantan), yakni modifikasi dari ke-2 sirip perut pari jantan yang digunakan sebagai alat kopulasi. Untuk pengujian perbandingan pari jantan dan pari betina dilakukan dengan uji Chi Kuadrat (Sugiyono, 2004), dengan rumus:

$$
X^{2}=\sum\left(f_{0}-f_{h}\right)^{2} / f_{n}
$$

di mana:

$$
\begin{aligned}
& X^{2}=\text { Chi kuadrat } \\
& f_{0}=\text { frekuensi yang diobservasi } \\
& f_{h}=\text { frekuensi yang diharapkan }
\end{aligned}
$$

Penentuan tingkat kematangan gonad pari $H$. gerrardi mengacu pada kriteria yang dikemukakan oleh Hoiden \& Raitt (1974) yang dibagi dalam 3 tingkat pada masing-masing jenis kelamin, yang meliputi:

\section{Pari jantan}

Kematangan seksual pada pari jantan dilakukan secara visual yaitu dengan melihat perkembangan dari mixopterygia (klasper). Pembagian tingkat kematangan seksual pada jantan adalah sebagai berikut:

a. Immature/belum matang (TKG I): klasper kecil, lemah, dan tidak mencapai ujung posterior sirip perut.

b. Maturing/berkembang (TKG II): klasper lebih besar dar, mencapai ujung posterior sirip perut, struktur internal dapat dilihat, lunak dan tidak bertulang.

c. Mature/matang (TKG III): klasper memanjang melebihi ujung posterior sirip perut, struktur internal dapat dilihat, keras, dan bertulang.

Pada pengamatan ini yang diukur yaitu panjang bagian luar dari klasper (clasper outer length).

\section{Pari betina}

Kematangan seksual pada pari betina harus dilihat dengan pengamatan secara internal. Pembagian tingkat kematangan seksual pada betina sebagai berikut:

a. Immature/belum matang (TKG I): ovarium kecil, hampir tidak terlihat, tidak ada telur, kelenjar cangkang sangat kecil, oviduk berdinding tebal, dan berwarna putih

b. Maturing/berkembang (TKG II): ovarium berisi telur yang berwarna putih, kelenjar cangkang sangat kecil, oviduk berdinding tebal, dan berwarna putih.

c. Mature/matang (TKG III): ovarium berisi telur yang berwarna kuning, kecuali segera setelah ovulasi pada spesies vivipar dan pada akhir musim pemijahan pada spesies ovipar, kelenjar cangkang membesar, dan oviduk menggelembung.

Pendugaan rata-rata lebar cawan pada waktu pertama kali matang gonad dilakukan dengan menggunakan metode Spearman-Karber (Udupa, 1986) yaitu sebagai berikut:

$$
m=X k+(X / 2)-\left(X \sum p i\right)
$$

di mana:

$$
\begin{aligned}
m= & \log \text { panjang ikan pada kematangan gonad } \\
& \text { pertama } \\
\mathrm{Xk}= & \log \text { nilai tengah kelas panjang di mana } \\
& \text { semua ikan }(100 \%) \text { sudah matang gonad } \\
\mathrm{pi}= & \text { proporsi ikan matang pada kelas ke-i di } \\
& \text { mana } \mathrm{pi}=\mathrm{ri} / \mathrm{ni} \text { apabila } \mathrm{ni}=\mathrm{ni}+1
\end{aligned}
$$

Maka panjang ikan pada waktu mencapa kematangan pertama (M) adalah:

$\mathrm{M}=\operatorname{antilog}(\mathrm{m})$ 
Jika á $=0,05$, maka batas-batas kepercayaan $95 \%$ dari $(\mathrm{m})$ adalah:

$$
\operatorname{antilog}\left(m \pm 1,96 \sqrt{ } x^{2}(p i-q i / n i-1)\right.
$$

Dalam perhitungan ini tingkat kematangan gonad I dan II dikelompokkan dalam kategori belum matang dan tingkat kematangan gonad III dimasukkan dalam kategori matang gonad.

\section{HASIL DAN BAHASAN}

Pari yang tertangkap dari Laut Jawa sebanyak 39 spesies dari 8 famili. Pari jenis Himantura gerrardi merupakan hasil tangkapan dominan dari tiap pusat pendaratan ikan di pantai utara Laut Jawa. Pari ini mendominasi sekitar $30,7 \%$ dari total hasil tangkapan pari seluruhnya. $H$. gerarrdi merupakan hasil tangkapan cantrang dan pancing senggol yang banyak ditemukan di Laut Jawa dan menduduk urutan pertama 5 pari yang dominan dari famili Dasyatidae.

H. gerarrdi dalam bahasa Inggris disebut whitespotted whipray (Carpenter \& Niem, 1999) Belum ada nama spesifik untuk pari tersebut, tetapi sering dikenal dengan nama pari mondol. Seperti terlihat dalam Gambar 1 berikut ini, $H$. gerrardi mempunyai karakteristik sebagai berikut cawan berbentuk rhomboid (jajaran genjang), badan tebal, lebar melampaui panjang (kira-kira 1,1 sampai dengan 1,2 kali panjang), puncak sirip dada menyempit, moncong berbentuk segitiga melebar dengan ujung kecil. Ekor berbentuk bulat memanjang (kira-kira 2,5 sampai dengan 3,0 lebar cawan). Bagian ekor seperti cambuk mulai di bawah duri sengat sedikit pipih melebar dekat pangkal, kebanyakan memiliki 1 duri sengat. Sirip perut kecil dan hampir berbentuk segitiga. Permukaan atas berwarna abuabu kecoklatan dengan totol-totol putih yang menyebar di seluruh atau setengah badan bagian belakang. Dasar ekor berwarna kecoklatan dengan totol-totol putih di sepanjang ekor
Pada umumnya pari ini ditangkap untuk diambil kulitnya, setelah itu dikeringkan atau disamak lalu digunakan sebagai bahan baku untuk tas, sepatu, dan dompet, juga dikonsumsi dagingnya.

\section{Hubungan Lebar Cawan dan Bobot}

Dari seluruh data kisaran lebar cawan pari dibagi dalam 2 kelompok yaitu, kelompok pari jantan dan pari betina. Data kisaran lebar cawan tersebut disajikan dalam Tabel 1

Ukuran lebar cawan pari jantan yang tertangkap pada umumnya lebih sempit daripada lebar cawan pari betina. Hampir pada setiap bulan pengamatan didapatkan modus lebar cawan pari jantan lebih kecil daripada modus lebar cawan pari betina (Tabel 1). Kisaran terbesar ukuran lebar cawan pari mondol jantan yaitu 21 sampai dengan $114 \mathrm{~cm}$ ditemukan pada bulan Juni 2002, sedangkan pada yang betina yaitu 10 sampai dengan $105 \mathrm{~cm}$ ditemukan pada bulan Oktober 2002.

Lebar cawan maksimum $H$. gerrardi hasil tangkapan dari Laut Jawa yaitu $114 \mathrm{~cm}$ pada pari jantan dan $105 \mathrm{~cm}$ pada pari betina. Hasil penelitian Carpenter \& Volker (1999) menemukan H. gerrardi di perairan barat Pasifik dengan lebar cawan maksimum $90 \mathrm{~cm}$ atau lebih dan di perairan Srilangka H. gerrardi ditemukan dengan lebar cawan maksimum $100 \mathrm{~cm}$ (Bruin et al., 1994). Dari keadaan ukuran lebar cawan pari yang didapatkan setiap bulan, dapat diketahui bahwa setiap bulan didapatkan variasi ukuran yang beragam.

Pengamatan terhadap contoh pari didapatkan pari betina 93 ekor dan 106 ekor pari jantan serta bobot pari betina berkisar antara 150 sampai dengan 3.000 g dan pari jantan berkisar antara 160 sampai dengan 13.000 g. Hasil analisis regresi mendapatkan persamaan hubungan lebar cawan bobot $H$. gerrardi $\mathrm{W}=0,0313 \mathrm{WD}^{2,9526}$ dengan nilai $\mathrm{R}^{2}=0,9715$ dengan nilai $b=2,9526$ untuk pari jantan; dan $W=0,0288$ $W^{2,9714}$ dengan nilai $R^{2}=0,9115$ dengan nilai $b=2,9714$ untuk pari betina (Gambar 2).

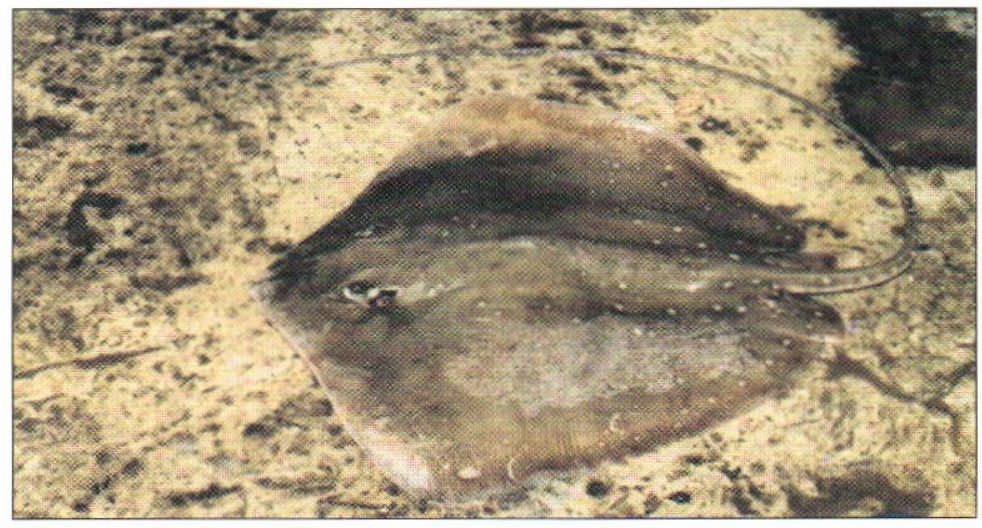

Gambar 1. Pari Mondol (Himantura gerrardi), famili Dasyatidae.

Figure 1. Mondol rays (Himantura gerrardi), family Dasyatidae 
Tabel 1. Kisaran lebar cawan width disk H. gerrardi yang tertangkap di perairan Laut Jawa Table 1. Disk width range of $\boldsymbol{H}$. gerrardi caught in Java Sea waters

\begin{tabular}{|c|c|c|c|c|c|c|c|c|c|c|}
\hline Bulan/Month & $\begin{array}{c}\text { Mei } \\
2002\end{array}$ & $\begin{array}{l}\text { Juni } \\
2002\end{array}$ & $\begin{array}{l}\text { Agst. } \\
2002\end{array}$ & $\begin{array}{l}\text { Sept. } \\
2002\end{array}$ & $\begin{array}{l}\text { Okt. } \\
2002\end{array}$ & $\begin{array}{l}\text { Nop. } \\
2002\end{array}$ & $\begin{array}{l}\text { April } \\
2003\end{array}$ & $\begin{array}{c}\text { Mei } \\
2003\end{array}$ & $\begin{array}{c}\text { Juli } \\
2003\end{array}$ & $\begin{array}{l}\text { Okt. } \\
2003\end{array}$ \\
\hline Seks & 3 & 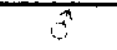 & क & $\overrightarrow{3}$ & 3 & $\bar{x}$ & 8 & 3 & $\hat{b}$ & 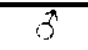 \\
\hline $\begin{array}{l}\text { Kisaran WD } \\
(\mathrm{cm})\end{array}$ & $18-23$ & $21-114$ & $17-88$ & $16-63$ & $14-78$ & $19-80$ & $14-82$ & $19-84$ & $22-88$ & $22-82$ \\
\hline $\begin{array}{l}\text { Rataan WD } \\
(\mathrm{cm})\end{array}$ & 20,3 & 48,1 & 50,7 & 24,2 & 39,9 & 45,2 & 41,8 & 37,7 & 55,2 & 46,3 \\
\hline Modus $(\mathrm{cm})$ & 20 & $50 ; 60$ & 50 & 30 & 50 & 50 & 30 & 30 & 60 & 50 \\
\hline $\mathrm{N}$ (ekor) & 15 & 39 & 83 & 58 & 277 & 221 & 98 & 272 & 60 & 53 \\
\hline Seks & q & 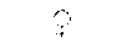 & 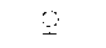 & 3 & $\widehat{\because}$ & 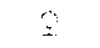 & 9 & 2 & 7 & 9 \\
\hline $\begin{array}{l}\text { Kisaran WD } \\
(\mathrm{cm})\end{array}$ & $18-85$ & $10-84$ & $16-91$ & $17,5-36$ & $10-105$ & $19-99$ & $18-90$ & $19-83$ & $16,5-77$ & $20-79$ \\
\hline $\begin{array}{l}\text { Rataan WD } \\
\text { (cm) }\end{array}$ & 54,1 & 48,8 & 54,4 & 23,0 & 41,7 & 53,3 & 44,4 & 40,2 & 44,5 & 46,9 \\
\hline $\begin{array}{l}\text { Modus (cm) } \\
N \text { (ekor) }\end{array}$ & $\begin{array}{l}70 \\
20\end{array}$ & $\begin{array}{l}70 \\
84\end{array}$ & $\begin{array}{c}60 \\
123\end{array}$ & $\begin{array}{l}30 \\
64\end{array}$ & $\begin{array}{c}60 \\
414\end{array}$ & $\begin{array}{c}70 \\
201\end{array}$ & $\begin{array}{l}30 \\
99\end{array}$ & $\begin{array}{c}30 \\
198\end{array}$ & $\begin{array}{c}30 \\
112\end{array}$ & $\begin{array}{l}50 \\
62\end{array}$ \\
\hline
\end{tabular}
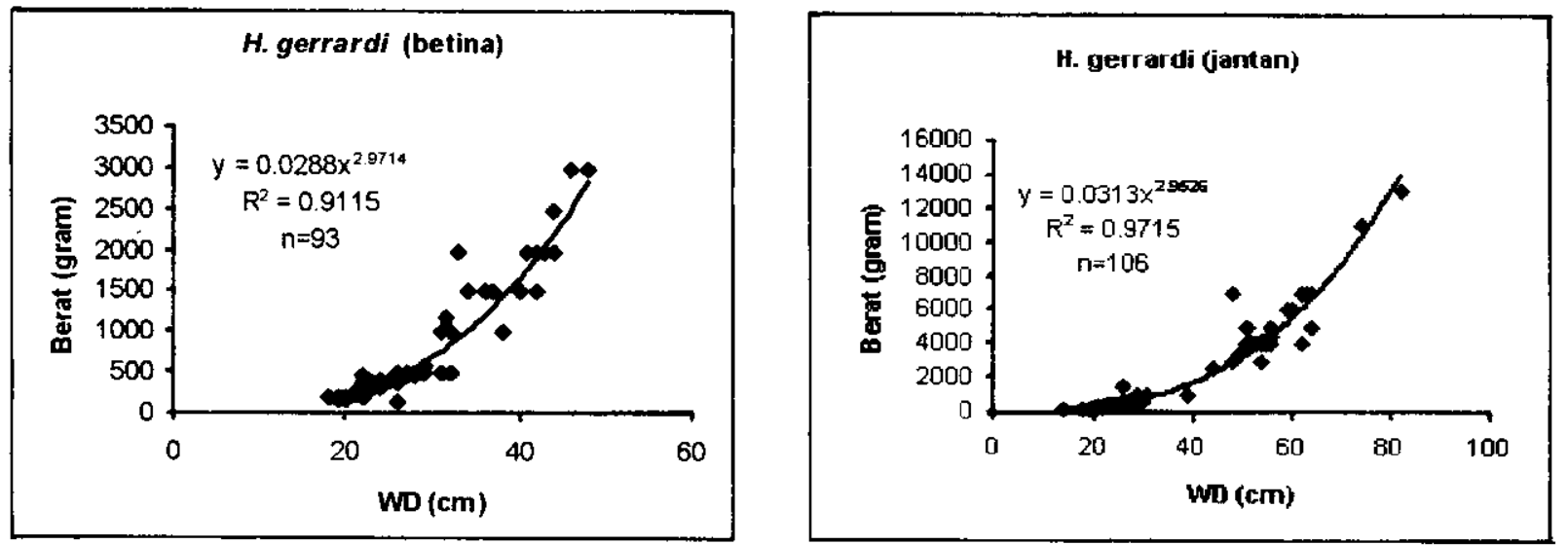

Gambar 2.

Hubungan lebar cawan dan bobot $H$. gerrardi betina dan jantan yang tertangkap di perairan Laut Jawa.

Figure 2. Disk width and weight relationship of female and male of $\boldsymbol{H}$. gerrardi caught in Java Sea waters.

Hasil pengujian nilai b yang diperoleh terhadap nilai 3 pada taraf $95 \%$ dan $99 \%$ baik pari jantan maupun betina menunjukkan sama dengan $3(b=3)$ sehingga dapat disimpulkan bahwa pertumbuhan $H$. gerrardi bersifat isometrik di mana pertambahan lebar cawan seimbang dengan pertambahan beratnya.

\section{Tingkat Kematangan Gonad}

Hasil pengukuran width disk pari jantan maupun betina, dikaitkan dengan tingkat kematangan gonadnya disajikan pada Tabel 2

Tabel 2. Kisaran lebar cawan width disk $H$. gerrardi berdasarkan pada tingkat kematangan gonad hasil tangkapan dari perairan Laut Jawa

Table 2. Range of disk width by maturity stages of $\boldsymbol{H}$. gerrardi caught from Java Sea waters

\begin{tabular}{lcccccc}
\hline & Immature & TKG I & Maturing & TKG II & Mature & TKG III \\
\hline Seks & 0 & 3 & 0 & & & \\
Kisaran WD (cm) & $16,5-66,0$ & $14,0-78,0$ & $24,0-69,0$ & $39,0-82,0$ & $26,0-71,0$ & $45,0-114,0$ \\
Rataan WD (cm) & 37,8 & 27,2 & 52,3 & 46,2 & 57,9 & 52,7 \\
Modus WD (cm) & 40 & 30 & 70 & 50 & 70 & 50 \\
n(ekor) & 24 & 443 & 4 & 271 & 40 & 461 \\
n(\%) & 35,29 & 37,7 & 5,88 & 23,1 & 58,82 & 39,2 \\
\hline
\end{tabular}


Jumlah pari jantan maupun betina yang tertangkap kebanyakan dalam kondisi matang gonad (tingkat kematangan gonad III atau mature), yaitu untuk pari betina $58,82 \%$ dan untuk pari jantan $39,20 \%$. Analisis lebar cawan Himantura gerrardi menurut tingkat kematangan gonad menunjukkan modus width disk pada tingkat kematangan gonad I pari jantan $30 \mathrm{~cm}$ dan pada pari betina $40 \mathrm{~cm}$. Pada tingkat kematangan gonad II, modus lebar cawan pari jantan $50 \mathrm{~cm}$ dan pari betina $70 \mathrm{~cm}$, pada tingkat kematangan gonad III modus lebar cawan pari jantan $50 \mathrm{~cm}$ dan pari betina $70 \mathrm{~cm}$. Dapat diduga bahwa pari jantan mencapai tingkat kematangan lebih dulu daripada pari betina. Ini diperkuat dengan perhitungan lebar cawan pertama kali matang gonad, pada pari jantan Lm $37,30 \mathrm{~cm}$ dengan kisaran $34,48 \mathrm{~cm}$ sampai dengan $40,36 \mathrm{~cm}$ dan pada pari betina Lm 48,22 cm dengan kisaran $44,92 \mathrm{~cm}$ sampai dengan $51,76 \mathrm{~cm}$.

Pengamatan bulanan tingkat kematangan gonad mendapatkan pari jantan maupun betina dalam semua tingkat kematangan gonad (Tabel 3). Persentase pari $H$. gerrardi jantan maupun betina dengan tingkat kematangan gonad I maupun tingkat kematangan gonad III didapatkan masing-masing 5 kali selama 10 bulan pengamatan. Untuk mengetahui apakah sumber daya pari tersebut sudah terganggu kelestariannya, maka perlu dibandingkan antara ukuran pertama kali tertangkap dengan ukuran pertama kali matang gonad. Ukuran pari pertama kali tertangkap (LC) yang dihitung melalui frekuensi kumulatif adalah $44 \mathrm{~cm}$ pada pari jantan dan $55 \mathrm{~cm}$ pada pari betina, maka Lc>Lm untuk pari jantan maupun betina, tetapi sumber daya $H$. gerrardi di Laut Jawa belum terancam kelestariannya karena sebelum pari tersebut tertangkap diduga sudah sempat memiiah.

Hasil analisis ukuran panjang klasper pari jantan dengan kematangan reproduksinya menunjukkan, diduga semakin tinggi tingkat kematangan gonad akan semakin panjang ukuran klaspernya, yang dapat dilihat dari rataan panjang klasper (Tabel 4).

Dengan demikian, dugaan bahwa kematangan reproduksi selain diikuti oleh bertambah panjangnya ukuran klasper juga diikuti oleh bertambah panjangnya ukuran lebar cawan. Hal ini, dapat dilihat pada grafik hubungan antara lebar cawan dengan panjang klasper (Gambar 3).

\section{Nisbah Kelamin}

Definisi dari nisbah kelamin adalah suatu angka yang menunjukkan perbandingan jumlah individu jantan dengan individu betina dalam suatu populasi. Secara alamiah, menurut Ball \& Rao (1984), di suatu perairan yang normal diperkirakan perbandingan jantan:betina adalah 1:1. Dari pengamatan terhadap 2.553 ekor $H$. gerrardi diperoleh hasil 1.175 ekor berkelamin jantan dan 1.378 ekor berkelamin betina. Sebaran perbandingan jumlah $H$. gerrardi yang berkelamin jantan dan betina setiap bulan pengamatan dapat dilihat dalam Tabel 5.

Apabila dilihat secara bulanan (bulan Mei 2002 sampai dengan Oktober 2003) terlihat perbandingan pari jantan dan betina bervariasi, sering kali jumlah pari jantan lebih sedikit dari jumlah pari betina terkecuali bulan Nopember 2002 dan Mei 2003

Tabel 3. Tingkat kematangan gonad pari $H$. gerrardi yang tertangkap di Laut Jawa

Table 3. Maturity stages of $\boldsymbol{H}$. gerrardi caught in Java Sea

\begin{tabular}{lcccc}
\hline \multicolumn{1}{c}{ Bulan/TKG } & TKG I $(\%)$ & TKG II (\%) & TKG III (\%) & N (ekor) \\
\hline Mei 2002 & 100 & 0 & 0 & 15 \\
Juni 2002 & 28 & 21 & $\mathbf{5 1}$ & 39 \\
Agustus 2002 & 10 & 25 & $\mathbf{6 5}$ & 83 \\
September 2002 & 98 & 0 & 2 & 58 \\
Oktober 2002 & $\mathbf{4 5}$ & 23 & 32 & 289 \\
Nopember 2002 & 15 & 36 & $\mathbf{4 9}$ & 221 \\
April 2003 & $\mathbf{4 0}$ & 26 & 35 & 98 \\
Mei 2003 & $\mathbf{5 4}$ & 15 & $\mathbf{3 1}$ & 262 \\
Juli 2003 & 6 & 23 & $\mathbf{7 2}$ & 53 \\
Oktober 2003 & 17 & $\mathbf{3 8}$ & $\mathbf{4 5}$ & 53 \\
\hline
\end{tabular}

Tabel 4 .

Kisaran CLO H. gerrardi (jantan), berdasarkan pada tingkat kematangan gonad hasil tangkapan dari perairan Laut Jawa

Table 4. Range of CLO by maturity stages of $\boldsymbol{H}$. gerrardi (male) caught from Java Sea waters

\begin{tabular}{lccc}
\hline H. gerrardi $(\delta)$ & TKG I/Immature & TKG II/Maturing & TKG III/Mature \\
\hline Kisaran CLO $(\mathrm{cm})$ & $0,5-3,0$ & $2,0-10,0$ & $2,0-10,0$ \\
Rataan CLO $(\mathrm{cm})$ & 0,8 & 3,4 & 4,6 \\
$\mathrm{n}($ ekor) & 443 & 271 & 461 \\
$\mathrm{n}(\%)$ & 37,7 & 23,1 & 39,2 \\
\hline
\end{tabular}




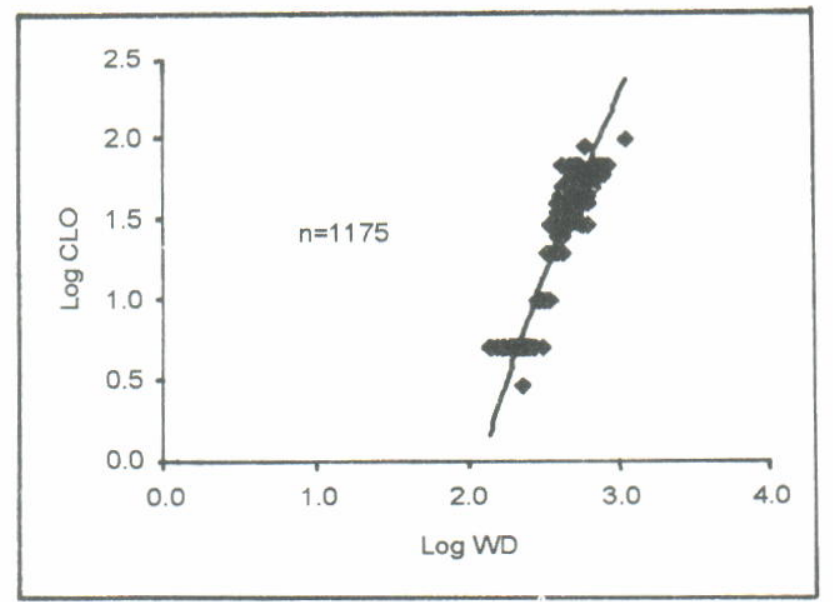

Gambar 3. Hubungan antara lebar dan cawan width disk dengan panjang klasper (CLO) H. gerrardi jantan yang tertangkap di perairan Laut Jawa.

Figure 3. Disk width and clasper outer length relationships of male $\boldsymbol{H}$. gerrardi caught in Java Sea waters.

Tabel 5. Nisbah kelamin H. gerrardi bulanan dari perairan Laut Jawa

Table 5. Monthly sex ratio of $\boldsymbol{H}$. gerrardi in Java Sea waters

\begin{tabular}{|c|c|c|c|c|c|c|c|c|c|c|}
\hline Bulan/Month & $\begin{array}{c}\text { Mei } \\
2002 \\
\end{array}$ & $\begin{array}{l}\text { Juni } \\
2002 \\
\end{array}$ & $\begin{array}{c}\text { Agst. } \\
2002\end{array}$ & $\begin{array}{l}\text { Sept. } \\
2002\end{array}$ & $\begin{array}{c}\text { Okt. } \\
2002 \\
\end{array}$ & $\begin{array}{l}\text { Nop. } \\
2002\end{array}$ & $\begin{array}{l}\text { April } \\
2003 \\
\end{array}$ & $\begin{array}{c}\text { Mei } \\
2003 \\
\end{array}$ & $\begin{array}{c}\text { Juli } \\
2003 \\
\end{array}$ & $\begin{array}{l}\text { Okt. } \\
2003 \\
\end{array}$ \\
\hline $\mathrm{N}$ (ekor) & 35 & 123 & 206 & 122 & 691 & 422 & 197 & 470 & 172 & 115 \\
\hline $\begin{array}{l}\text { Seks ratio } \\
3: 0\end{array}$ & $1,0: 1,3$ & $1,0: 2,2$ & $1,0: 1,5$ & $1,0: 1,1$ & $1,0: 1,5$ & $1,0: 0,9$ & $1,0: 1,0$ & $1,0: 0,7$ & $1,0: 1,9$ & $1,0: 1,2$ \\
\hline
\end{tabular}

Analisis selanjutnya, dari Tabel 5. terlihat perbandingan keseluruhan ikan pari jantan dan betina 1,00:1,17 (1.175 ekor:1.378 ekor). Analisis Chi kuadrat yang menunjukkan hasil berbeda nyata $\left\{X^{2}=34,995 ; \quad X^{2} \quad\right.$ Tabel $_{(0,05)}=16,919 ; \quad X^{2} \quad$ tabel $_{(0.01)}$ $=21,666\}$ yang berarti perbandingan kelamin antara pari jantan dan betina tidak seimbang. Selaras dengan pernyataan Wahyuono et al. dalam Rohy (2001), bahwa apabila jantan dan betina seimbang atau betina lebih banyak dapat diartikan bahwa populasi tersebut ideal untuk mempertahankan kelestarian, sebaliknya apabila jantan lebih banyak dari betina dapat diartikan bahwa populasi tersebut tidak ideal untuk mempertahankan kelestarian atau cenderung punah. Dengan demikian, kesinambungan populasi pari Himantura gerrardi di perairan Laut Jawa berjalan dengan baik.

\section{KESIMPULAN}

1. Hubungan panjang bobot pari Himantura gerrardi bersifat isometrik, dengan demikian pertambahan lebar cawan seimbang dengan pertambahan bobotnya.

2. Tingkat kematangan gonad pari $H$. gerrardi di Laut Jawa bervariasi dan yang terbanyak ditemukan adalah pada tingkat kematangan gonad I dan tingkat kematangan gonad III.
3. Ukuran pertama kali matang pari jantan adalah pada lebar cawan $37,30 \mathrm{~cm}$ dan pada pari betina pada lebar cawan $48,22 \mathrm{~cm}$.

4. Perbandingan kelamin pari $H$. gerrardi jantan dan betina yang tidak seimbang dengan jumlah betina lebih banyak, berarti bahwa kesinambungan populasi pari $H$. gerrardi di perairan Laut Jawa terjamin dengan baik.

\section{DAFTAR PUSTAKA}

Bal, D. V. \& Rao, K. V. 1984. Marine fisheries. Tata Mc. Graw-Hill Publishing Company Limited. New Delhi. p 5-24.

Bruin, G. H.P, B. C. Russell, \& A. Bogusch. 1994. The marine fishery resources of Sri Lanka. FAO. Rome. p 79-90

Carpenter, K. E. \& V. H. Niem. 1999. The living marine resources of Western Central Pacific. Vol.3: Bathoid fishes, chimaeras, and bony fish. Part: 1 (Elopidae to linophrynidae). FAO. Rome.

Castro, J L., C. M. Woodley, \& L. L. Brudek. 1999. A preliminary evaluation of the status of shark species. FAO Fisheries. Tech. Pap. (380): 72 p. 
Compagno, L. J. V. 1998. Shark, p. 687-1396. In Carpenter, K. E. \& V. H. Niem (eds.), The living marine resources of the Western Central Pacific. Vol.2. Cephalopods, crustaceans, holothurians, and sharks. FAO. Rome.

FAO. 2000. Fisheries management: 1. Conservation and management of sharks. FAO Tech. Guidelines for Responsible Fisheries. Suppl. 1. FAO. Rome. $37 \mathrm{p}$.

Holden, M. J. \& D. F. S. Raitt. 1974. Manual of fisheries science. Part 2: Methods of resources investigation and their application. FAO. Rome. $p$. 131-132.

Last, P. R. \& J. D. Stevens. 1994. Sharks and rays of Australia. CSIRO. Australia. 513 p.

Rohy, I. C. 2001. Studi tentang aspek biologi dan aspek perikanan ikan cucut yang didaratkan di pelabuhan perikanan Pantai Prigi, Jawa Timur Karya IImiah Praktek Akhir. Program Diploma 4. Sekolah Tinggi Perikanan. Jakarta. 63 hal.

Sainsbury, K. J., P. J. Kailola, \& G. G. Leyland. 1985 Continental shelf fishes of Northern and NorthWest Australia. An illustrated guide. CSIRO and Clouston \& Hall and Peter Pownall Fisheries. Information Service. Canberra. Australia. $375 p$.

Sugiyono. 2004. Statistika untuk penelitian. Penerbit C. V. Alfabeta. Bandung. 306 hal.

Tarp. T. G. \& P. J. Kailola. 1982. Trawled fishes of southern Indonesia and northern Australia. ADABDGF-GTZ. Singapore. $406 \mathrm{p}$.

Udupa, K. S. 1986. Statistical method of estimating the size at first maturity in fishes. Fishbyte 4(2): 8 10. ICLARM. 
